\title{
Remembering 9/11, Moral Injury, COVID-19 and Measuring Religion, Spirituality and Health
}

\author{
Lindsay B. Carey ${ }^{1}$ - Jeffery Cohen ${ }^{2} \cdot$ Harold G. Koenig ${ }^{3,4} \cdot$ Terrence Hill $^{5}$. \\ Ezra Gabbay $^{6} \cdot$ Carl Aiken $^{7,8}$. Jacinda R. Carey ${ }^{1}$
}

Accepted: 1 September 2021 / Published online: 7 September 2021

(c) The Author(s), under exclusive licence to Springer Science+Business Media, LLC, part of Springer Nature 2021

\begin{abstract}
Four key themes are covered in this issue of JORH, namely: (1) the catastrophic events of 11 September 2001, (2) the syndrome of moral injury, (3) the ongoing calamity of COVID-19, and finally, (4) the validation, translation and use of measurement instruments/scales assessing religion, spirituality and health.
\end{abstract}

Keywords 9/11 · Moral injury · COVID-19 $\cdot$ Religion/spiritual measurement scales · Chaplains

\section{Introduction}

We start this issue remembering the tragic events of 11 September 2001, which produced substantial consequences for the world for the next two decades and which, despite the United Nations best efforts, looks to be ongoing-at least for those in Afghanistan. A reflection and review of published articles is presented about 9/11 in JORH as a tribute to those who died as innocent victims. We hope there will be additional reflections subsequently published in JORH on this topic. This JORH issue also presents, for the first time, a collection of articles relating to moral injury - a biopsychosocial-spiritual syndrome affecting those having to endure the aftermath of having been involved in war zones (whether directly or indirectly), or being engaged in other severely traumatic circumstances where individuals may have transgressed their moral values or observed others doing so. Articles relating to the ongoing dynamics of COVID-19 are again featured in this issue, which has become the most dominant theme thus far across seven issues of JORH. Finally, there is an extensive section within this issue for all researchers interested in developing or translating measures of spirituality or religion.

Lindsay B. Carey

Lindsay.Carey@latrobe.edu.au

Extended author information available on the last page of the article 


\section{September 2001}

Twenty years since the fatal day of the 11th of September, it is time to reflect. No doubt, 9/11 is long gone for some, now in the distant past, and they do not wish to recall or relive the memory but instead move forwards. Others however will remember the anguish as if it were yesterday. In this issue, Associate Professor Jeffery Cohen, former President of the US Association of Mental Health Clergy (now the Association of Professional Chaplains) and distinguished recipient of the Order of Australia (OA), writes a personal reflection about his experiences on the day of 9/11, and considers some of the articles previously published in JORH which have reflected on this unbelievably tragic event.

\section{Moral Injury}

Although varying to some degree in concept and still with no consensus definition, the term 'moral injury' is slowly gaining recognition across military, healthcare, and first responder sectors. This issue of JORH brings together several articles relating to moral injury, religion, and health. It commences with an opening paper by Professor Harold Koenig describing moral injury as an increasingly recognized and widespread syndrome with considerable impact on mental health and well-being. This is then followed by a series of articles which consider (1) moral injury as a moral paradox, (2) collaboration of mental health clinicians and community clergy to address moral injury symptoms, (3) the treatment of moral injury in US veterans with PTSD using a structured chaplain intervention, (4) moral injury among Australian veterans and the role of chaplains, (5) chaplains' perspectives considering the topic of moral injury morbidity, and (6) a forgiveness interview protocol called 'narrative therapy writing' for the treatment of moral injury. Finally, two additional articles have been added to this section that relate to morality: (7) what morality and religion have in common with health and the formation of moral competence, and lastly, (8) the role of a worldview in moral case deliberation.

\section{COVID-19}

COVID-19 continues to plague the world. In this particular issue, we present articles that relate to Christian countries and Islamic countries. Those from Christian countries examine (1) religion in the USA during the pandemic from a medical perspective, (2) the impact of COVID-19 on the religious lives of black families living with dementia in the USA, (3) the mental health burden of the pandemic among members of the Orthodox Church, (4) the impact of COVID-19 on Orthodox Christian devotional practices, rituals, and religious pilgrimages, (5) excess deaths among the Amish and Mennonites due to the pandemic, (6) social distancing as a recontextualization of Filipino values and Catholic religious practices, (7) religiosity and 
meaning making during COVID-19 among adolescents in Poland, and finally, (8) a novel intervention by healthcare chaplains called "This is My Story" which involves interdisciplinary medical teams delivering care to non-communicative patients.

Concerning Islam, authors in this issue have examined (1) Islamic religious practice and efforts to protect against the virus, (2) Islamic social support through religion and psychological well-being in Indonesia, (3) the stress, coping and trust levels of Turkish healthcare professionals during the pandemic, (4) the perceptions of spiritual dryness in Iran during COVID-19, and (5) an ethical roadmap for prioritizing medical resources within Muslim societies during COVID-19, (6) the relationship of depression, anxiety and stress among Turkish pregnant women, (7) attitude of married Muslim women regarding family planning during COVID-19, (8) determing the religious coping styles of adolscents in Turkey during COVID-19, (9) funeral processes and Islamic religious leaders in Indonesia, and (10) lastly a study from Israel about undergound COVID-19 hospitals for Haredim. Finally, while not specifically mentioning COVID-19, we conclude within this section with an article by Dr. John Nezlek which considers the 'relationships between religiosity and naturally occurring social interactions'. This article examines whether comfort derived from religious beliefs and practices (e.g. prayer) is positively related to the quality of daily social experiences. We can only look forward to the end of this pandemic so that we can resume the full benefits of naturally occurring social interactions.

\section{Measuring Religion and Health}

In a previous issue, JORH (2021b) published a special section on 'measuring religion and health' which focused on scales for empirically assessing religiosity/spirituality (see JORH 60:1, p. 458-595). These included the 'Chinese Spiritual Coping Scale' (CSCS), 'Brief Religious Coping Scale' (Brief RCOPE), 'Ethicotherapy Quality of Life Questionnaire (EQLQ), 'Belief into Action Scale' (BIAC), 'Daily Spiritual Experience Scale' (DSES), and the 'Intensity of Religious Experience Scale' (IRES). These previously published scales involved samples from China, Chile, Czech, England, Morocco, Poland, Slovakia, Iran, and the USA. As noted in the editorial of JORH 60 (1), 'The variety and utilization of instruments for considering religiosity and/or spirituality are increasingly diverse' (Carey, 2021, p. 2).

This current JORH issue also considers additional research discussing and analysing various religious/spiritual measures. The first article written by Professor Harold Koenig and Dr. Faten Al Zaben forms an introduction to this section by summarizing methodological issues with regard to the 'psychometric validation and translation of religious/spiritual measures'. Essentially, Koenig and Al Zaben (2021) argue that there is a standard procedure for: (1) determining the psychometric properties of scales, whether this involves the development of new scales or the administration of older established scales in different environments (countries, cultures, or languages), and (2) the translation of existing scales into another language for administration in populations whose language differs from that in which the scales were originally developed (and the subsequent establishment of reliability and validity of those translated scales) (Koenig \& Al Zaben, 2021). 
The standard scientific procedures outlined in Koenig and Al Zaben's (2021) article should now be followed when developing and translating measures for use in studies examining the relationship between religiosity/spirituality (R/S) and health. For authors planning to submit papers of this type in the future to JORH (i.e. scale psychometrics and/or translation), it is highly recommended that authors take stock of this publication, as the procedures described in Koenig and Al Zaben's (2021) article will be the standard by which such papers are judged. Indeed, well-designed scales form the foundation for much of the quantitative clinical research conducted today in the psychological, social, behavioural, and physical health sciences, and this is also true for studies examining the relationship between religion and health.

Accompanying Koenig and Al Zaben's article in this section are pieces examining the psychometric properties of (1) the Five-Item Francis Attitude Towards Christianity Scale among Columbian patients, (2) the Religious and Spiritual Coping (Portuguese RCOPE) in a Portuguese population, (3) the Brief Religious Coping Measure (Persian RCOPE) in Persian-speaking older adults, (4) the Italian language version of the Religious Beliefs and Mental Illness Stigma Scale (I-RBMIS), (5) the Scale of Abandonment by God (SAG), (6) the Duke University Religion Index (DUREL) in Portuguese cancer patients undergoing chemotherapy, (7) the 10-item Belief into Action Scale (BIAC) in a multicultural inpatient setting, and finally, (8) the Polish adaptation of the 'Spiritual Intelligence Self-Report Inventory'.

In addition to the above, this issue also includes articles on the (9) Religious Perfectionism Scale among undergraduate students in Iran, (10) the Spanish version of the Spiritual Care Competence Questionnaire, (11) the Spiritual/Religious Perfectionism Scale in Iran, (12) the Persian version of the Religious Orientation Scale among Iranian patients with cancer, (13) the Turkish Adaptation of the Spirit at Work Scale among production sector employees, (14) the well tested and utilized Spiritual Well-Being Questionnaire-SHALOM, (15) the Gratitude Questionnaire in India, and lastly, (16) a summary of findings relating to the Spiritual Needs Questionnaire in research and clinical applications. All these scales reflect considerable regional, societal, and cultural diversity involving American, Columbian, Iranian, Italian, Polish, Portuguese, Spanish, and Turkish populations.

Finally, to conclude this section, there is a book review by Professor Jeffery Levin summarizing a substantial monograph by Amy L. Ai, et al (2021) titled, 'Assessing Spirituality in a Diverse World' (Springer), which presents some 20 plus scales for assessing religiosity, spirituality, and non-religiosity (see Table 1).

The necessity, substantiation, and utilization of such scales indicate that there should be little doubt that religious and spiritual beliefs (and related practices) form the basis for how people in many countries live their lives and interact with others. Furthermore, it is clear that religious/spiritual beliefs and practices are intimately related in one way or another to the mental, social, behavioural, and physical health of individuals and their communities. The establishment of psychometrically and culturally valid measures of religion/spirituality for use in different countries, societies, and languages is absolutely essential given the growth of this research field as it expands throughout the world. 
Table 1 Assessing spirituality in a diverse world—scales and measures (Ai et al., 2021). Source: Table developed from Ai, A. L., Wink, P., Paloutzian, R. F., \& Harris, K. A. (Eds.). (2021). Assessing spirituality in a diverse world. Switzerland: Springer. https://doi.org/10.1007/978-3-030-52140-0

\begin{tabular}{ll}
\hline Name of scale/measure & Name of scale/measure \\
\hline $\begin{array}{l}\text { Spiritual well-being scale (SWBS) } \\
\text { Post-christianity spirituality scale (PCSS) }\end{array}$ & $\begin{array}{l}\text { Spiritual Jihad measure/s (SJM) } \\
\text { Santa Clara strength of religious faith questionnaire } \\
\text { (SCSRFQ) }\end{array}$ \\
$\begin{array}{l}\text { Connection of soul scale (COS) } \\
\text { Multidimensional existential meaning scale }\end{array}$ & $\begin{array}{l}\text { Perceived spiritual support scale (PSSS) } \\
\text { (MEMS) }\end{array}$ \\
$\begin{array}{l}\text { Religious and spiritual struggles scale (RSS) } \\
\text { Reverence in religious and secular contexts meas- }\end{array}$ & $\begin{array}{l}\text { Spiritual modelling self-efficacy measure (SMSE) } \\
\text { ure (RRSC) }\end{array}$ \\
$\begin{array}{l}\text { Felf-expansiveness level form } \\
\text { Using private prayer for coping (UPPC) }\end{array}$ & $\begin{array}{l}\text { Measure of diverse adolescent spirituality } \\
\text { Spiritual orientation inventory (SOI) }\end{array}$ \\
$\begin{array}{l}\text { Measure of atheist discrimination Experiences } \\
\text { Expressions of spirituality inventory (ESI) }\end{array}$ & MADE) \\
Psychological measure of Islamic religiousness & scale (MANRIS) \\
(PMIR) & Reasons for atheists and agnostics for nonbelief in \\
Buddhist trait mindfulness scale (BTMS) & god's existence scale (RANGES) \\
& Dimensions of secularity (DoS) \\
& Humanism scale (H-scale) \\
\hline
\end{tabular}

\section{Call for Papers}

As noted in the current and previous editorials, this year marks two decades since the devastating event of 11 September 2001. Authors are encouraged to submit their reflections upon 9/11 for future issues of this journal. Please feel free to contact one of the editors if you wish to discuss a potential paper. Submissions are made through the Editorial Manager on the JORH web site: https://www.springer.com/journal/ 10943/submission-guidelines.

\section{References}

Ai, A. L., Wink, P., Paloutzian, R. F., \& Harris, K. A. (Eds.). (2021). Assessing spirituality in a diverse world. Springer. https://doi.org/10.1007/978-3-030-52140-0

Carey, L. B. (2021). COVID-19, nursing, pediatrics and measuring religion and health. Journal of Religion and Health, 60(1), 1-4. https://doi.org/10.1007/s10943-020-01174-6

JORH. (2021b). Journal of Religion and Health, 60(1). Springer. https://link.springer.com/journal/10943/ volumes-and-issues/60-1

JORH. (2021a). Journal of Religion and Health, 60(5). Springer. https://link.springer.com/journal/10943/ volumes-and-issues/60-5

Koenig, H. G., \& Al Zaben, F. (2021). Psychometric validation and translation of religious and spiritual measures. Journal of Religion and Health, 60(5). https://doi.org/10.1007/s10943-021-01373-9

Publisher's Note Springer Nature remains neutral with regard to jurisdictional claims in published maps and institutional affiliations. 


\section{Authors and Affiliations}

\section{Lindsay B. Carey ${ }^{1}$. Jeffery Cohen ${ }^{2} \cdot$ Harold G. Koenig ${ }^{3,4} \cdot$ Terrence Hill $^{5}$. Ezra Gabbay $^{6} \cdot$ Carl Aiken $^{7,8} \cdot$ Jacinda R. Carey ${ }^{1}$}

Jeffery Cohen

jeffrey.cohen@nd.edu.au

Harold G. Koenig

Harold.Koenig@duke.edu

Carl Aiken

caiken@drew.edu

Jacinda R. Carey

Jacinda.Carey@latrobe.edu.au

1 Public Health Palliative Care Unit, La Trobe University, Melbourne, Australia

2 School of Medicine (Sydney), University of Notre Dame Australia, St Vincent's Private Hospital Sydney, New South Wales, Australia

3 Department of Psychiatry and Behavioral Sciences, and Department of Medicine, Duke University Health Systems, Durham, NC, USA

4 Division of Psychiatry, Department of Medicine, King Abdulaziz University, Jeddah, Saudi Arabia

5 The University of Texas at San Antonio, San Antonio, TX, USA

6 Division of General Internal Medicine, Department of Medicine, Hospital Medicine Section, Weill Cornell Medicine, New York, NY, USA

7 Drew University Alumni, Maddison, NJ, USA

8 Royal Women's and Children's Hospital, Adelaide, South Australia, Australia 